\title{
PENERAPAN MODEL PEMBELAJARAN PEMAKNAAN PADA MATERI TITRASI ASAM BASA UNTUK MENGEMBANGKAN KARAKTER SISWA KELAS XI SMA
}

\author{
Sumarni ${ }^{1}$ \\ Tukiran ${ }^{2}$ \\ Leny Yuanita ${ }^{2}$ \\ 1) SMA Negeri 1 Krian Sidoarjo \\ 2) Pascasarjana Prodi Pendidikan Sains Universitas Negeri Surabaya \\ e-mail:Sumarni.krian@gmail.com
}

\begin{abstract}
The research purposed to know the implementation result of the learning model of pemaknaan on the topic of acid base titration could be used to develop on the eleventh grade students' character of SMAN 1 Krian. In the research, it was used preexperimental research by the replication of three times using the design of one group pretest and posttest design. This reseach used the data analysis of qualitative descriptive to apply on lesson plan (RPP). The learning outcome of students' character was analized by qualitative descriptive and would be continued by Mann-Whitney test for it's replication. The results were reported that: (1) The lesson plan (RPP) was made based on syntax of the learning model of pemaknaan was conducted very well, (2) The implementation of this model could develop the students' character.
\end{abstract}

Keywords: Implementation; learning outcome; pembelajaran pemaknaan; titration

\begin{abstract}
Abstrak: Penelitian ini bertujuan untuk mengetahui hasil penerapan model pembelajaran pemaknaan pada materi titrasi asam basa terhadap perkembangan karakter siswa kelas XI SMAN 1 Krian. Jenis penelitian yang digunakan adalah pre-eksperimen replikasi tiga kali melalui One Group Pretest and Posttest Design. Analisis data yang digunakan adalah deskriptif kualitatif untuk keterlaksanaan RPP. Hasil belajar karakter siswa dianalisis dengan deskriptif kualitatif yang dilanjutkan dengan uji Mann-Whitney untuk antar hasil replikasi. Hasil penelitian menunjukkan RPP yang disusun sesuai sintaks model pembelajaran pemaknaan berjalan dengan sangat baik, penerapan model pembelajaran pemaknaan dapat mengembangkan karakter siswa.
\end{abstract}

Kata-kata Kunci: Hasil belajar; pembelajaran pemaknaan;penerapan dan titrasi

\section{Pendahuluan}

Penyelenggaraan pendidikan karakter di sekolah harus berpijak kepada nilai-nilai karakter dasar, yang selanjutnya dikembangkan menjadi nilai-nilai yang lebih tinggi (yang bersifat tidak absolut atau bersifat relatif) sesuai dengan kebutuhan, kondisi, dan lingkungan sekolah itu sendiri. Contoh karakter utama dalam mata pelajaran IPA adalah ingin tahu, berpikir logis, kritis, kreatif dan inovatif, jujur, bergaya hidup sehat, percaya diri, menghargai keberagaman, disiplin, mandiri, bertanggung jawab, peduli lingkungan, cinta ilmu (Kemendiknas, 2010). Karakter utama dalam mata pelajaran kimia meliputi rasa ingin tahu, jujur, peduli lingkungan, senang membaca, kritis, kreatif, toleran, peduli sosial, religius, disiplin, komunikatif, mandiri, cinta tanah air, dan cinta damai (Kemendiknas, 2010b).

Berkaitan dengan pendidikan karakter, ada beberapa siswa SMAN 1 Krian yang bermasalah. Pada tahun ajaran 2008-2009, ada tiga siswa tidak naik kelas meningkat menjadi sembilan siswa pada tahun ajaran 2009-2010 disebabkan karakternya yang tidak baik yaitu mengambil barang milik orang lain, tidak disiplin (sering tidak masuk sekolah tanpa ijin), merusak fasilitas kelas dan prestasi rendah (Data dari BK, 2009 dan 2010). Disisi lain, pada tahun ajaran 2010-2011 semester 1, peneliti mengamati sikap negatif siswa yang sering terlambat masuk kelas, mengumpulkan tugas tidak tepat waktu, dan menyontek pada saat ulangan. Pada saat melakukan pratikum, beberapa siswa nampak masih belum siap pratikum, ada yang bersikap di luar kegiatan pratikum, dan ada beberapa siswa tidak memakai jas lab. Hal ini nampak kurangnya dilakukan disiplin, jujur dan tanggung jawab oleh beberapa siswa. Oleh karena itu, peneliti ingin melatih siswa membiasakan berbuat jujur, disiplin, dan tanggung jawab melalui penerapan model pembelajaran pemaknaan pada materi kimia di SMAN 1 Krian. Karakter jujur, disiplin dan tanggung jawab berasal dari nilai karakter dasar dan terpancar dari hasil olah hati serta berhubungan dengan kesadaran diri. Ketiga karakter ini juga merupakan karakter utama dalam mata pelajaran IPA. Model pemaknaan mengajari siswa untuk memaknai berbagai gejala IPA dan dihubungkan dengan karakter yang dikembangkan sehingga timbul kesadaran diri.

Berdasarkan latar belakang masalah di atas, peneliti mengajukan rumusan masalah "Apakah penerapan model pembelajaran pemaknaan pada materi titrasi asam basa dapat digunakan untuk mengembangkan karakter siswa 
kelas XI SMAN 1 Krian?", secara rinci meliputi: 1) Bagaimana keterlaksanaan pembelajaran kimia menggunakan perangkat model pembelajaran pemaknaan pada materi titrasi asam basa?, 2) Bagaimana hasil belajar afektif (karakter) siswa setelah mengikuti proses pembelajaran pemaknaan?

\section{Metode Penelitian}

Jenis penelitian yang digunakan adalah preeksperimen replikasi (R) tiga kali melalui One Group Pretest and Posttest Design. Subyek uji coba siswa kelas XI IPA SMAN 1 Krian sejumlah tiga kelas (R1, R2 dan R3). Pengambilan data dilaksanakan pada bulan November tahun ajaran 2011-2012 di SMAN 1 Krian.

Instrumen penelitian meliputi: lembar pengamatan (keterlaksanaan RPP, karakter siswa) dan tes. Instrumen tes diperlukan untuk mengetahui ketuntasan hasil belajar siswa terhadap materi titrasi asam basa setelah KBM dengan model pemaknaan.

Pengumpulan data menggunakan teknik observasi (pada saat proses pembelajaran maupun pada saat pelaksanaan tes ) terhadap keterlaksanaan RPP model pemaknaan, dan karakter siswa (jujur, disiplin, tanggung jawab). Teknik analisis data meliputi: 1) Data keterlaksanaan model pembelajaran melalui teknik analisis deskriptif kualitatif untuk mengetahui persentase dan kategori keterlaksanaan RPP sesuai rubrik. 2) Data hasil melatih pengembangan karakter siswa dianalisis melalui analisis deskriptif kualitatif. Selanjutnya hasil belajar karakter siswa pada tiga kelas replikasi dianalisis dengan statistik nonparametrik uji Mann-Whitney menggunakan SPSS 18.

\section{HaSil DAN PEMbahasan}

\section{A. Keterlaksanaan RPP}

Hasil pengamatan keterlaksanaan RPP pada uji coba 2 menunjukkan rata-rata kemampuan guru (peneliti) dalam melaksanakan pembelajaran yang meliputi: pendahuluan, kegiatan inti, penutup dan pengelolaan waktu termasuk kategori sangat baik. Hal ini berarti seluruh tahapan pada sintaks model pembelajaran pemaknaan telah terlaksana dengan baik.

Rata-rata nilai reliabilitas RPP 1 dan 2 pada kelas R1 $=98,23 \%$, kelas R2 $=98,19 \%$, dan kelas R3 $=97,66 \%$, ini berarti intrumen pengamatan keterlaksanaan RPP yang digunakan berkategori baik. Suatu instrumen pengamatan digolongkan baik bila memiliki reliabilitas di atas atau sama dengan 75\% (Borich, 1994). Hasil reliabilitas yang baik ini menunjukkan selisih skor yang diberikan dua pengamat tidak terlalu jauh. Hal ini karena dua pengamat sudah mempelajari terlebih dahulu RPP yang disusun peneliti dan cara memberi skor.

Keterlaksanaan RPP yang baik karena peneliti mempersiapkan dengan baik dalam mengimplementasi sintaks model pembelajaran pemaknaan pada materi titrasi asam basa sesuai dengan prinsip dasar model ini yaitu berpusat pada siswa dan ditunjang kualitas perangkat pembelajaran yang valid serta respon positif siswa dalam mengikuti proses pembelajaran.

Perangkat pembelajaran yang telah dirancang dengan baik dan dapat terlaksana dengan baik ini menyebabkan respon siswa positif terhadap kualitas pembelajaran. Respon yang baik dapat meningkatkan motivasi siswa untuk beraktivitas lebih baik sehingga dapat meningkatkan hasil belajarnya. RPP yang peneliti buat lebih banyak pratikum dan diskusi memberi peluang lebih banyak siswa untuk meningkatkan aktivitasnya dalam proses pembelajaran. Nur dan Wikandari (1998 dalam Siskandar, 2009: 178) menyebutkan agar aktivitas belajar siswa dapat lebih efektif dan efisien, proses pembelajaran perlu dikelola dengan baik sehingga hasil belajar dapat meningkat.

TABEL I. SKOR RATA-RATA KETERLAKSANAAN RPP PADA TIGA KELAS REPLIKASI

\begin{tabular}{|c|c|c|c|c|c|c|c|c|c|c|c|c|c|}
\hline \multirow{2}{*}{ No. } & \multirow{2}{*}{ ASPEK YANG DIAMATI } & \multicolumn{6}{|c|}{ RPP1 } & \multicolumn{6}{|c|}{ RPP 2} \\
\hline & & $\mathrm{R} 1$ & $\mathrm{~K}$ & R2 & $\mathrm{K}$ & R3 & $\mathrm{K}$ & $\mathrm{R} 1$ & $\mathrm{~K}$ & R2 & $\mathrm{K}$ & R3 & $\mathrm{K}$ \\
\hline I. & Pelaksanaan & & & & & & & & & & & & \\
\hline A. & PENDAHULUAN & & & & & & & & & & & & \\
\hline 1. & \begin{tabular}{llr} 
Memotivasi & siswa & dengan \\
menunjukkan & \multicolumn{2}{c}{ larutan dalam } \\
botol yang tidak diketahui \\
konsentrasinya.
\end{tabular} & 4,0 & SB & 4,0 & SB & 4,0 & SB & - & & - & & - & \\
\hline 2. & $\begin{array}{c}\text { Mengingatkan materi prasyarat } \\
\text { /sebelumnya }\end{array}$ & 3,8 & SB & 3,3 & $\mathrm{~B}$ & 3,7 & SB & 4,0 & SB & 4,0 & SB & 3,5 & SB \\
\hline 3. & $\begin{array}{l}\text { Menyampaikan tujuan } \\
\text { pembelajaran }\end{array}$ & 4,0 & SB & 4,0 & SB & 4,0 & SB & 4,0 & SB & 4,0 & SB & 4,0 & SB \\
\hline
\end{tabular}




\begin{tabular}{|c|c|c|c|c|c|c|c|c|c|c|c|c|c|}
\hline \multirow{2}{*}{ No. } & \multirow{2}{*}{ ASPEK YANG DIAMATI } & \multicolumn{6}{|c|}{ RPP1 } & \multicolumn{6}{|c|}{ RPP 2} \\
\hline & & $\mathrm{R} 1$ & $\mathrm{~K}$ & $\mathrm{R} 2$ & $\mathrm{~K}$ & R3 & $\mathrm{K}$ & R1 & $\mathrm{K}$ & $\mathrm{R} 2$ & K & R3 & K \\
\hline B. & KEGIATAN INTI & & & & & & & & & & & & \\
\hline 1. & $\begin{array}{l}\text { Menginformasikan konsep titrasi } \\
\text { asam basa yang ada di hand out } \\
\text { atau LKS }\end{array}$ & 3,8 & SB & 3,7 & SB & 3,8 & SB & 3,5 & SB & 3,5 & SB & 3,5 & SB \\
\hline 2. & $\begin{array}{c}\text { Membagi siswa ke dalam } \\
\text { kelompok-kelompok belajar }\end{array}$ & 4,0 & SB & 4,0 & SB & 4,0 & SB & 4,0 & SB & 4,0 & SB & 4,0 & SB \\
\hline 3. & $\begin{array}{l}\text { Membimbing kelompok dalam } \\
\text { eksperimen/diskusi atau } \\
\text { membimbing kelompok dalam } \\
\text { menjawab pertanyaan di LKS 04 }\end{array}$ & 4,0 & SB & 4,0 & SB & 4,0 & SB & 4,0 & SB & 4,0 & SB & 4,0 & SB \\
\hline 4. & $\begin{array}{c}\text { Menunjuk beberapa kelompok } \\
\text { untuk melakukan presentasi hasil } \\
\text { eksperimen/diskusi }\end{array}$ & 3,7 & SB & 3,8 & SB & 4,0 & SB & 4,0 & SB & 4,0 & SB & 4,0 & SB \\
\hline 5. & $\begin{array}{l}\text { Memberikan umpan balik } \\
\text { terhdap konsep yang telah } \\
\text { disampaikan }\end{array}$ & 4,0 & SB & 4,0 & SB & 4,0 & SB & 4,0 & SB & 4,0 & SB & 4,0 & SB \\
\hline 6. & $\begin{array}{l}\text { Mendiskusikan pemaknaan } \\
\text { terhadap gejala / fenomena pada } \\
\text { konsep yang telah disampaikan }\end{array}$ & 3,5 & SB & 3,5 & SB & 3,5 & SB & 4,0 & SB & 4,0 & SB & 4,0 & SB \\
\hline 7. & Evaluasi dan refleksi & 3,5 & SB & 3,2 & $\mathrm{~B}$ & 2,8 & B & 4,0 & SB & 4,0 & SB & 4,0 & SB \\
\hline C. & PENUTUP & & & & & & & & & & & & \\
\hline 1. & $\begin{array}{c}\text { Merevieu pembelajaran dengan } \\
\text { meminta siswa untuk } \\
\text { menyimpulkan apa yang telah } \\
\text { dipelajari } \\
\end{array}$ & 3,7 & SB & 3,7 & SB & 3,2 & B & 4,0 & SB & 4,0 & SB & 4,0 & SB \\
\hline 2. & $\begin{array}{c}\text { Guru memberikan tugas rumah } \\
\text { atau mengimformasikan postest } \\
\text { pada RPP } 2\end{array}$ & 4,0 & SB & 4,0 & SB & 4,0 & SB & 4,0 & SB & 4,0 & SB & 4,0 & SB \\
\hline II. & PENGELOLAAN WAKTU & 3,3 & $\mathrm{~B}$ & 3,5 & SB & 3,5 & SB & 4,0 & SB & 4,0 & SB & 4,0 & SB \\
\hline & RELIABILITAS & $98,0 \%$ & & $97,9 \%$ & & $97,6 \%$ & & $98,9 \%$ & & $98,9 \%$ & & $97,9 \%$ & \\
\hline & erata reliabilitas RPP 1 dan 2 & & $\mathrm{R} 1=\mathrm{C}$ & $3,23 \%$ & & & $\mathrm{R} 2=\mathrm{C}$ & $8,19 \%$ & & & $\mathrm{R} 3=9$ & $7,66 \%$ & \\
\hline
\end{tabular}

\section{B. Hasil Belajar Karakter Siswa}

Hasil belajar karakter siswa telah mencapai tahap responding, karena siswa telah merespon positif karakter sesuai indikator dan rubrik yang ditetapkan. Data hasil belajar karakter siswa diperoleh dari hasil pengamatan karakter siswa selama proses pembelajaran dan pada saat tes tulis yang dilakukan oleh dua pengamat dan dibantu peneliti. Hasil belajar karakter yang dikembangkan meliputi disiplin diri, jujur dan tanggung jawab.

Hasil belajar karakter disiplin diri siswa yang mendapat predikat A (sangat baik) R1 $=80 \%, \mathrm{R} 2=100$ $\%$ dan $\mathrm{R} 3=83 \%$, sedangkan yang lain mendapat predikat $\mathrm{B}$ (baik) $\mathrm{R} 1=20 \%$ dan $\mathrm{R} 3=17 \%$. Rata-rata reliabilitas pengamatan karakter disiplin kelas R1, R2 dan R3 berturut-turut: $99,4 \%, 99,1 \%, 99,6 \%$.

Hasil belajar karakter tanggung jawab siswa yang mendapat predikat A (sangat baik) $\mathrm{R} 1=87 \%, \mathrm{R} 2=100$ dan $\mathrm{R} 3=80 \%$, sedangkan yang lain mendapat predikat $\mathrm{B}$ (baik) R1 = $13 \%$ dan R3 = 20\%. Rata-rata reliabilitas pengamatan karakter tanggung jawab pada kelas replikasi $\mathrm{R} 1, \mathrm{R} 2=99,5 \%$ dan $\mathrm{R} 3=99,6 \%$.

Hasil belajar karakter jujur siswa yang mendapat predikat A (sangat baik) R1 = $93 \%, \mathrm{R} 2=100 \%$ dan R3 $=93 \%$, sedangkan yang lain mendapat predikat B (baik)
$\mathrm{R} 1$ dan $\mathrm{R} 3=3 \%$. Rata-rata reliabilitas pengamatan karakter jujur ketiga kelas replikasi $=100 \%$.

Hasil uji Mann-Whitney pada hasil belajar pengembangan karakter disiplin siswa kelas R1-R2 dan R2-R3 menunjukkan ada perbedaan pada taraf signifikan $5 \%$, sedangkan kelas R1-R3 menunjukkan tidak ada perbedaan hasil belajar pengembangan karakter disiplin siswa pada taraf signifikan 5\%. Hasil uji Mann-Whitney pada hasil belajar pengembangan karakter tanggung jawab dan jujur siswa ketiga kelas replikasi yaitu R1-R2, R1-R3 dan R2-R3 menunjukkan tidak ada perbedaan hasil belajar karakter tersebut pada taraf signifikan 5\%.

Hasil uji Mann-Whitney menunjukkan karakter disiplin dan tanggung jawab dapat dipengaruhi oleh penerapan model pemaknaan, tetapi ada perbedaan hasil belajar karakter disiplin pada kelas R1-R2 dan R2-R3, karena Ho ditolak pada taraf signifikan 5\%. Adanya perbedaan hasil belajar karakter kelas replikasi tersebut menunjukkan karakter juga dipengaruhi faktor internal yaitu kesadaran diri dari masing-masing individu sebagai pembelajar karena karakter yang dikembangkan bersumber dari olah hati. Perbedadan ini disebabkan kelas R2 mempunyai kedisiplinan yang lebih tinggi dibanding kelas R1 dan R3. 
Hasil pengamatan terhadap pengembangan tahapan belajar karakter disiplin dan tanggung jawab ketiga kelas replikasi mengalami peningkatan, mulai dari pertemuan pertama sampai keempat. Hal ini karena guru selalu memberi penguatan pada karakter yang dikembangkan melalui pemaknaan materi titrasi asam basa. Guru menjelaskan tentang pengertian, pentingnya karakter yang dikembangkan dan menyampaikan kata-kata bijak untuk memberi motivasi agar siswa tetap berkarakter baik. Setiap selesai fase pemaknaan diikuti fase refleksi agar siswa dapat mengoreksi diri terhadap karakter yang dikembangkan selama KBM.

Hasil uji Mann-Whitney untuk karakter jujur Ho diterima, artinya tidak ada perbedaan karakter jujur pada ketiga kelas replikasi. Semua siswa mendapat nilai A kecuali dua orang siswa pada kelas R1 dan R3 mendapat nilai B. Hasil pengamatan terhadap karakter jujur tampak bahwa ada siswa yang tidak jujur pada postes THB produk di kelas R1, R3 dan THB proses di R3, tetapi pada THB pretes maupun melaporkan data hasil pratikum semua jujur. Prestasi yang baik ini karena pada saat ulangan dijaga dengan ketat dan kesadaran siswa tentang kejujuran begitu juga pada saat pratikum. Namun jika ada siswa yang tidak jujur pada saat tes, bisa disebabkan tidak bisa mengerjakan soal, ingin mendapat nilai di atas KKM, rasa tidak percaya diri dan ingin membantu teman.

Pemaknaan tentang kejujuran kurang begitu berarti karena sejak awal yaitu pretes semua jujur dan selama proses pembelajaran siswa juga jujur dalam melaporkan hasil pratikumnya, tetapi karena faktor kepentingan ingin mendapat nilai yang baik masih dijumpai siswa tidak jujur yaitu bertanya atau mencontek pekerjaan temannya. Jadi kejujuran sangat berhubungan dengan kepentingan seseorang untuk mencapai tujuannya, kecuali orang yang benar-benar sudah berkarakter jujur dan memahami arti kejujuran tahan terhadap gangguan darimanapun. Oleh karena itu peneliti menyarankan agar penilaian kejujuran sebaiknya minimal dua topik, sehingga kita bisa mengetahui ada atau tidak ada peningkatan karakter jujur antara hasil belajar postes topik 1 dan topik 2 atau setiap akhir pertemuan diberi postes jika waktu masih memungkinkan. Pada saat pretes $100 \%$ siswa bisa mengerjakan dengan jujur karena siswa mengetahui tes hanya untuk mengukur kemampuan awal yang tidak ada hubungannya dengan nilai. Namum demikian hasilnya sangat menggembirakan jika dibandingkan dengan tes-tes sebelumnya yang peneliti amati karena peneliti juga mengajar di kelas ini. Memberi pemaknaan berfungsi untuk penguatan dan menjaga ketat pada saat ulangan adalah memberikan kondisi tidak menyenangkan agar siswa terlatih untuk membiasakan berbuat jujur. Siswa berbuat tidak jujur bisa disebabkan adanya kesempatan untuk melakukannya.
Hasil belajar pengembangan karakter disiplin, tanggung jawab, dan jujur, menunjukkan prestasi yang baik. Menurut teori belajar perilaku, dalam proses belajar mengajar, jika kita ingin agar siswa mempertahankan perilaku yang dilatihkan maka beri dia penguatan, sebaliknya bila menginginkan agar perilaku tidak dilakukan lagi, maka berilah konsekuensi yang tidak menyenangkan (punisher). Pemaknaan materi titrasi asam basa sepanjang proses pembelajaran bertujuan untuk memberi penguatan pada karakter yang dikembangkan bahkan dapat digunakan sebagai model untuk pembentukan karakter. Pemberian konsekuensi yang sesegera mungkin sangat berpengaruh positif terhadap perilaku selanjutnya. Setiap ada pelanggaran, guru berusaha segera menegur dan menunjukkan kekurangankekurangannya dengan 'hati'.

Karakter jujur, disiplin dan tanggung jawab berasal dari nilai karakter dasar dan terpancar dari hasil olah hati serta berhubungan dengan kesadaran diri. Pemaknaan adalah salah satu tahapan pada sintaks model pembelajaran pemaknaan yang ditujukan untuk menyentuh hati dan emosi siswa agar dapat memunculkan rasa empati, simpati, dan kepedulian, sehingga siswa termotivasi untuk melakukan perilaku positif yang dimodelkan (Ibrahim, 2008). Pemaknaan diberikan untuk mengetahui karakter baik, setelah siswa mengetahui pentingnya karakter baik bahkan bahayanya jika dilanggar, diharapkan siswa menyadari dan mempunyai keinginan berbuat baik, selanjutnya menjadi kebiasaan dalam tindakan.

Hasil penelitian menunjukkan ada hubungan berbanding lurus antara karakter disiplin dan tanggung jawab. Siswa yang berpredikat B pada karakter disiplin, maka pada karakter tanggung jawab rata-rata juga mendapat nilai B. Siswa yang mempunyai disiplin tinggi sudah pasti siswa tersebut bertanggung jawab. Siswa dapat mengumpulkan tugas tepat waktu berarti siswa tersebut disiplin dan bertanggung jawab. Tanda-tanda orang disiplin antara lain dapat menghargai waktu dan menggunakannya sebaik-baiknya, tidak suka menunda pekerjaan, kalau masih bisa dikerjakan saat itu juga, menaati segala tata tertib dan merasa terganggu pikirannya jika melanggar aturan tersebut.

Siswa yang memiliki disiplin belajar yang tinggi akan tercermin pada beberapa sikap dan perilaku, yakni: memiliki tanggung jawab dan komitmen belajar yang tinggi, memiliki motivasi belajar intrinsik yang tinggi dan memanfaatkan waktu luang yang efisien, memiliki rencana waktu belajar yang efektif, serta kegiatankegiatan belajarnya terarah pada tujuan belajar (Pangayow, 2006). Seseorang yang bertanggung jawab adalah seseorang yang siap menerima tugas dan 
kewajiban baik sebagai anak, siswa, karyawan, pimpinan dan lain-lain (Agustian, 2009).

Dengan demikian sangat masuk akal jika siswa kelas R2 mendapat rata-rata nilai hasil belajar produk paling tinggi. Karena siswa yang mempunyai kedisiplinan dan tanggung jawab yang baik mampu meregulasi diri dengan baik. Gunarsa (1991) dalam Susanto (2006), menyatakan kebiasaan disiplin diri dan disiplin waktu akan mendukung kelancaran perkembangan kognitif sehingga anak mempunyai keberhasilan prestasi yang optimal.

Hasil penelitian ini ditemukan bahwa kelas R2 semua siswa mendapat predikat A pada tiga karakter yang dikembangkan. Predikat ini menunjukkan kelas R2 ratarata berkarakter lebih baik daripada kelas replikasi lainnya, ternyata rata-rata hasil belajar produk mendapat nilai tertinggi. Kelas R3 yang rata-rata predikat karakter paling rendah ternyata mendapat nilai rata-rata hasil belajar produk paling rendah.

Pendidikan karakter yang diterapkan secara sistematis dan berkelanjutan, seorang siswa akan menjadi cerdas emosinya. Kecerdasan emosi ini adalah bekal penting menyongsong anak dalam meraih masa depan, karena seseorang akan lebih mudah dan berhasil menghadapi segala macam tantangan kehidupan, termasuk tantangan untuk berhasil secara akademis. Hasil penelitian di negara Amerika Serikat, Jepang, Cina, dan Korea menyatakan bahwa implementasi pendidikan karakter yang tersusun secara sistematis berdampak positif pada pencapaian akademik. Hasil studi Dr. Marvin Berkowitz dari University of Missouri-St. Louis, menunjukkan peningkatan motivasi siswa sekolah dalam meraih prestasi akademik pada sekolah-sekolah yang menerapkan pendidikan karakter (Afandi, 2011).

\section{SIMPULAN DAN SARAN}

\section{A. Simpulan}

Setelah dilakukan penelitian dan analisis data dapat peneliti simpulkan sebagai berikut: 1) RPP penerapan model pembelajaran pemaknaan terlaksana dengan sangat baik. 2) Hasil belajar karakter rata-rata mendapat nilai sangat baik dan baik. Ini menunjukkan ada respon positif siswa untuk menerapkan dalam tindakan sesuai indikator yang ditetapkan.
Dengan demikian berdasarkan rumusan masalah utama dalam penelitian ini, dapat disimpulkan bahwa penerapan model pembelajaran pemaknaan pada materi titrasi asam basa dapat digunakan untuk mengembangkan karakter siswa.

\section{B. Saran}

Berdasarkan diskusi hasil penelitian, peneliti menyarankan agar dilakukan penelitian lebih lanjut penerapan model ini pada materi kimia yang lain dan untuk mengembangkan karakter jujur sebaiknya dalam waktu yang lebih lama dari penelitian ini atau minimal dua topik.

\section{Daftar Pustaka}

Afandi, R. 2011. "Integrasi Pendidikan Karakter dalam Pembelajaran IPS di Sekolah Dasar”. Jurnal Ilmu Pendidikan Pedagogia. Vol.1, No.1, pp. 85-98.

Agustian, A.G. 2009. Bangkit dengan 7 Budi Utama. Jakarta: PT. Arga Publishing.

Borich, G.D. 1994. Observation Skills for Effective Teaching. New York: Macmillan Publishing Company.

Ibrahim, M. 2008. Model Pembelajaran IPA Inovatif Melalui Pemaknaan. Jakarta: Tim Peneliti Balitbang.

Kemendiknas. 2010. Pengembangan Pendidikan Budaya dan Karakter Bangsa Pedoman Sekolah. Jakarta: Balitbang Puskur.

Pangayow, W. 2006. "Pembinaan Disiplin Belajar Mahasiswa". Jurnal Penelitian dan Pendidikan. Vol.3 No.3, pp. 358-372.

Siskandar, 2009. "Keefektifan Pendekatan Cooperative Learning dalam Meningkatkan Aktivitas dan Hasil Belajar mahasiswa". Jurnal Ilmu Pendidikan. Jilid 16, No. 3, pp. 178-185.

Yamin, S. dan Heri, K. 2009. SPSS Complete Teknik Analisis Statistik Terlengkap dengan Software SPSS. Jakarta: Salemba Infotek. 